\title{
Payment schedule, sequence of choice, and cooperation in the Prisoner's Dilemma game'
}

GaRY W. EVANS and ChaRles M, GRumbaugh

BUREAU OF CHILD RESEARCH AND THE UNIVERSITY OF KANSAS

Eighty colleae $S s$ in like-sexed dyads played a 100 trial Prisoner's Dilemma game with a nonmatrix format. Payment schedule and sequence of choices were each varied at two levels and were not found to be related to the amount of cooperation to a statistically significant extent. Sex of the dyad was not related to cooperation, which supported previous data from games of less than 100 trials. The overall level of cooperation was comparable to the two previous studies using the same format.

The problem was to determine the effect of sequence of choice, payment schedule, and sex of the dyad on cooperation in a Prisoner's Dilemma game.

Method

The Ss were volunteers from a pool of University of Kansas introductory psychology students who are required to participate in $5 \mathrm{hr}$. of experimentation as Ss. Five male dyads and five female dyads were randomly assigned to each of the four conditions created by two levels of choice sequence and two levels of payment method.

All Ss played a nonmatrix version of the Prisoner's Dilemma game for 100 trials. The Prisoner's Dilemma is characterized by a conflict in the joint gain available and the individual gain available to the players, and is usually presented by giving each player a matrix similar to Fig. 1. The players independently choose between $\mathrm{A}$ and $\mathrm{B}$ and the resulting choice combination would determine the payoff. With the nonmatrix format each player chooses between having the $\mathrm{E}$ give him one point by placing a chip on "Give me one" and having the $\mathrm{E}$ give the other player three points by placing the chip on "Give him three." This choice situation is strategically equivalent to that presented in Fig. 1. (A more complete description of both presentation formats may be found in Evans \& Crumbaugh, in press.)

The Ss were brought into the experimental room and seated on opposite sides of a shield by the $E$ who then read them the appropriate set of instructions. In front of each S was a board with the two choices "Give me one" and "Give him three" and each Shad to meet a criterion of two correctly answered questions about the payoff combinations. After the instructions, play was begun and the responses and payoffs were recorded by $\mathrm{E}$. At the end of 100 trials, the appropriate payments were made and the Ss were dismissed.

Two sequences of choices were used: (1) alternating, and (2) simultaneous. In the alternating choice conditions, one player was randomly designated to choose first and thereafter the two players took turns choosing.
Prisoner's Dilemma Payoff Matrix

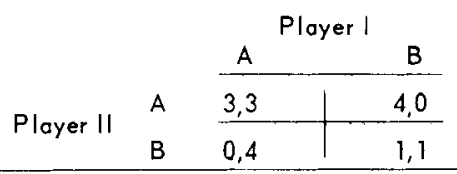

Fig. 1. The first number in each cell is player l's payoff for that choice combination. Each player chooses either $A$ or $B$ and the resultant combination determines the payoffs to each player.

Each $\mathrm{S}$ was informed of the payoffs after each decision. In the simultaneous conditions, both Ss chose at the same time and were informed of the payoffs after both had chosen.

The two methods of payment were: (1) per trial payoff, and (2) a single trial random payoff suggested by Radlow (1965). In the per trial payoff conditions, the points assigned after each choice were totaled at the end of the experiment and exchanged for money at the rate of one cent for each point. In the Radlow payoff conditions, one of the 100 trials was randomly selected at the end of the experiment by drawing a number from a box. The Ss were then paid $\$ 1.00$ for each point they had received on that trial.

\section{Results}

The number of cooperative ("give him three") responses for each pair of Ss was recorded. Table 1 presents the mean per cent cooperation by sex of the dyad for each of the four treatment conditions. The treatment effects and sex of dyad were found to be statistically inslgnificant when analyzed via an F-test and a median test. An analysis of the first 50 trials vs. the last 50 also failed to reveal a difference. Discussion

In a previous study, Radlow (1965) presented a method of increasing the apparent size of the payoffs in a Prisoner's Dilemma by paying larger amounts for a single trial rather than smaller amounts for a number of trials. Since one of the possible objections to conclusions drawn from Prisoner's Dilemma research is that in "real life" the size of the payoff is usually in much larger amounts than those normally used in Prisoner's Dilemma research, this procedure seemed to

Table 1. Mean per cent cooperation per 100 trial game.

\begin{tabular}{lcccc} 
& \multicolumn{2}{c}{ Simultaneous } & \multicolumn{2}{c}{ Alternoting } \\
\hline Sex & Radlow & Per Trial & Radlow & Per trial \\
\hline Male & 42.7 & 67.5 & 70.1 & 69.3 \\
Female & 61.4 & 59.3 & 49.6 & 62.0 \\
\hline
\end{tabular}


offer itself as a partial test of the objection. In the study by Radlow, however, the random procedure involved a random number of table and extensive instructions to explain its use, and further, no control group was employed. The experiment reported here utilized a control and the much simpler randomizing method of drawing numbers from a box. The results did not substantiate the hypothesis that method of payment would make a difference in cooperation when the actual possible gain for the two methods was the same. Although caution must be exerted in interpreting negative results, they would seem to indicate that differences in the "apparent" size of the payoff (when the actual possible payoff is the same) does not effect cooperation in the Prisoner's Dilemma game to any great extent.

Another question bearing upon the relative generality of Prisoner's Dilemma research is that the usual game is played under conditions of simultaneous choice, whereas, in "real life" most decisions seem to be made on a nonsimultaneous basis and often as a result of what the other person just did. The alternating vs. simultaneous choice comparison provided no support for the notion that nonsimultaneous choices produces more cooperation.

The analysis of the effects of sex support previous research by Lutzker (1961), Bixenstine \& Wilson (1963), and Sampson \& Kardush (1965) that there is no sex main effect in games of less than 100 trials in length, although Rapoport (1965) has presented data to indicate that sex effects do show up in games of more than 100 trials.

The overall level of cooperation in the study was 60 per cent. This figure closely approximates the findings of two previous studies using the same format (Evans \& Crumbaugh, in press; Crumbaugh \& Evans, 1965) in which rates of cooperation were 63 per cent and 58 per cent respectively.

\section{References}

Bixenstine, V. E., \& Wilson, K. V. Effects of level of cooperative choice by the other player on choices in a Prisoner's Dilemma game. Part II. J. abnorm. soc. Psychol, 67, 1963, 139-147.

Crumbaugh, C. M., \& Evans, G. W. Parsons Research Center Working Paper No. 116. "Presentation format, stooge strategies, and cooperative behavior in a Prisoner's Dilemma," 1965.

Evans, G. W., \& Crumbaugh, C. M. Effects of Prisoner's Dilemma format on cooperative behavior. J. Pers. soc. Psychol, in press.

Lutzker, P. R. Sex role, cooperation, and competition in a twoperson non-zero-sum game. $J$. conflict Res., 1961. 5, 366-368.

Radlow, R. An experimental study of "cooperation" in the Prisoner's Dilemma game. J. conflict Res., 1965, 9, 221-227.

Rapoport, A., \& Chammah, A. M. Sex differences in factors contributing to the level of cooperation in the Prisoner's Dilemma Game. J. Pers soc. Psychol., 1965, 2, 831-838.

Sampson, E. E., \& Kardush, M. Age, sex, class and race differences in responses to a two-person non-zero-sum game. $J$. conflict Res., 1965, 9, 212-220.

\section{Note}

1. This work was supported in part by NINDB Grant Number 5-T1NB-5362-04 and by NICHHD grant number HD-00870-03. 